\title{
Modelling Covid-19 under uncertainty: what can we expect?
}

\author{
Meimei Wang ${ }^{1} \cdot$ Steffen Flessa $^{1}$ \\ (c) The Author(s) 2020 / Published online: 3 June 2020
}

\section{JEL Classification I100}

The Covid-19 pandemic constitutes one of the greatest medical, social, economic and political challenges for the last decades. Millions have been infected, hundred thousands have died and the economic loss reaches totals that are gigantic even for macro economists used to big numbers. Within a short period of time an enormous number of far-reaching decisions have to be made within a highly complex system of interdependent virological, pharmaceutical, behavioural, legal, social and economic frameworks. Hardly ever before we have experienced such a strong set of policies based on so little evidence as in the last few months since Sars-Cov- 2 became a life-threatening challenge for the health systems and the population of this world $[1,2]$.

Covid-19 affects all subsystems and it is obvious that fighting this disease goes far beyond the health care arena. This high complexity and dynamics calls for reliable decision-bases. In particular, health decision-makers have to know the epidemiologic and economic consequences of interventions. As wrong decisions might result in loss of life, chaotic over-burdening of health care services, unemployment and even social unrest affecting millions, evidencebased policy making would be a must - but there is no evidence about forecasting the future.

What can scientists and in particular health economists contribute to this struggle for evidence? Seeing the high complexity and dynamics of the Covid-19 system, modelling becomes a must to support health-policy decisions [3]. Already very early, models predicting the spread of this disease were published. Markov and System Dynamics models usually divide the population into compartments of being susceptible to the disease (S), actively infected with the disease (I), and recovered (or dead) and no longer contagious (R), i.e., they use a SIRmodel structure [4-7] (Fig. 1). As Covid-19 is an infectious

Steffen Flessa

steffen.flessa@uni-greifswald.de

1 University of Greifswald, Friedrich-Loeffler-Straße 70,

17487 Greifswald, Germany disease, the likelihood of falling sick depends on the share of the infectious population in the total population, i.e., the infection risks changes with every person who is infected, falls sick, dies or recovers. Consequently, homogenous Markov chains where the transition probabilities are constant are inadequate for modelling infectious diseases. Inhomogeneous Markov chains [8] where the transition probabilities are re-calculated for every time interval are identical with System Dynamics Models [7, 9] if the time intervals are sufficiently frequent.

Common models used to forecast infectious diseases are (system) dynamics and discrete event simulations [10]. The system dynamics model [11-13] defines difference equations for the healthy, infected, sick and immune population, e.g.

$H_{t+1}=H_{t}-\frac{H_{t}}{H_{t}+I_{t}+S_{t}+M_{t}} \cdot \frac{I_{t}+S_{t}}{H_{t}+I_{t}+S_{t}+M_{t}} \cdot H_{t} \cdot r$

$I_{t+1}=I_{t}+\frac{H_{t}}{H_{t}+I_{t}+S_{t}+M_{t}} \cdot \frac{I_{t}+S_{t}}{H_{t}+I_{t}+S_{t}+M_{t}} \cdot H_{t} \cdot r-\frac{I_{t}}{i}$

$S_{t+1}=S_{t}+\frac{I_{t}}{i}-S_{t} \cdot m-\frac{S_{t}}{s}$

$T_{t+1}=T_{t}+S_{t} \cdot m$

$M_{t+1}=M_{t}+\frac{S_{t}}{S}$

With

\begin{tabular}{ll}
\hline Variables & Description \\
\hline$H_{t}$ & Healthy in $t$ \\
$I_{t}$ & Incubating in $t$ \\
$S_{t}$ & Sick in $t$ \\
$M_{t}$ & Immune in $t$ \\
$T_{t}$ & Death cases in $t$ \\
\hline
\end{tabular}




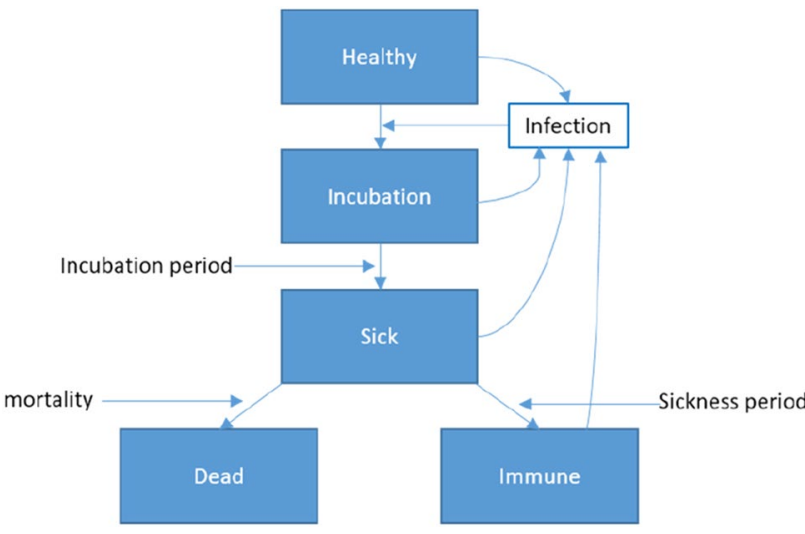

Fig. 1 Covid-19 model structure

\begin{tabular}{llll}
\hline Constants & & Value & Source \\
\hline$H_{0}$ & Healthy in $t=0$ & $1,000,000$ & \\
$m$ & Mortality rate & 0.05 & {$[14]$} \\
$s$ & Sickness period & $14 \mathrm{~d}$ & {$[15]$} \\
$i$ & Incubation period & $5 \mathrm{~d}$ & {$[15]$} \\
$R_{0}$ & Basic reproductive rate & 3 & {$[16]$} \\
$r$ & Infection rate per day: $r=R_{0} /(i+s)$ & 0.158 & \\
\hline
\end{tabular}

Based on this model we can calculate the spread of the disease and simulate the impact of interventions (see Fig. 2).

System Dynamics Models can be much more complex, i.e., they can distinguish between different population groups (e.g. age-sets, general health status of population) and include non-infectious periods or different levels of health care. However, all System Dynamics Models are compartment models assuming that a population within one compartment is homogenous. In reality, people show different behaviour and social interactions which is in particular relevant for the spread of a contagious disease. Consequently, in particular the first weeks of a disease or an intervention cannot be properly analysed with system dynamics models. Instead, simulation models with individuals (discrete event simulation, DES) [17, 18] and with individual characteristics (agent-based simulation, ABS) $[19,20]$ are used to forecast the (early) spread of a disease. Here individuals with pre-defined behaviour interact and infections of individuals are computed. If the SIR-model is sufficiently complex and a higher number of individuals exists in each compartment, SIR-models and ABS will lead the similar results while early stages of a disease outbreak or of an intervention will be more correct with ABS [21, 22].

The formulation and computation of even the best Covid19 models are under severe uncertainty [23]. Firstly, there is uncertainty considering biological and medical facts, i.e., most medical parameters are unknown or strongly uncertain. For instance, we do not know exactly the relevance of the viral load, the determinants of the case fatality rates (e.g., chronic-degenerative diseases, obesity), the influence of earlier infections with other Corona viruses or the general immunity (e.g., caused by a BCG-vaccination). This uncertainty challenges modelling and policy advice. In addition, some parameters might change in the course of the disease due to mutation of the virus.

Secondly, the vagueness of medical care structures and data is another source of uncertainty in disease modelling. For instance, the situation in French and Italian hospitals during the most severe Covid-19 crises in March 2020 did definitely not follow official guidelines of intensive care. Until today there is no standard of treatment of patients
Fig. 2 Covid-19 model SIRresults (own)

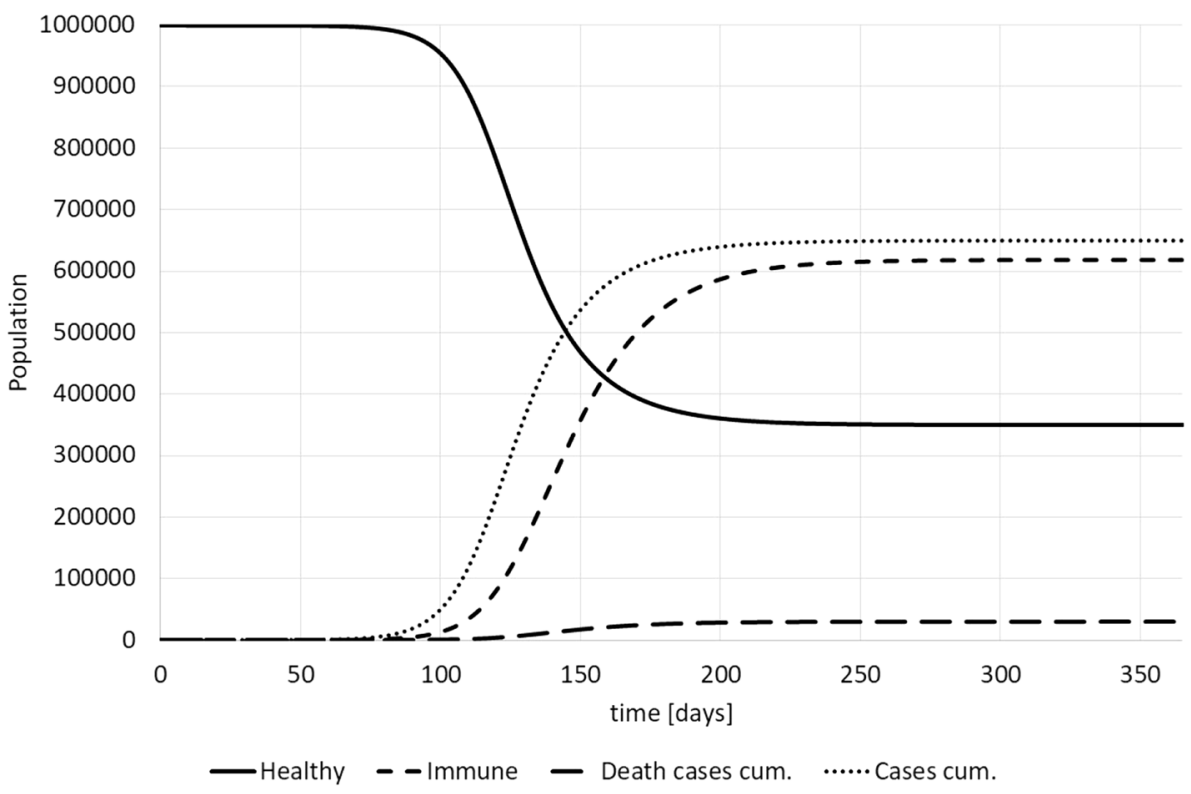


Fig. 3 Sick patients and infection rate (results from own simulations)

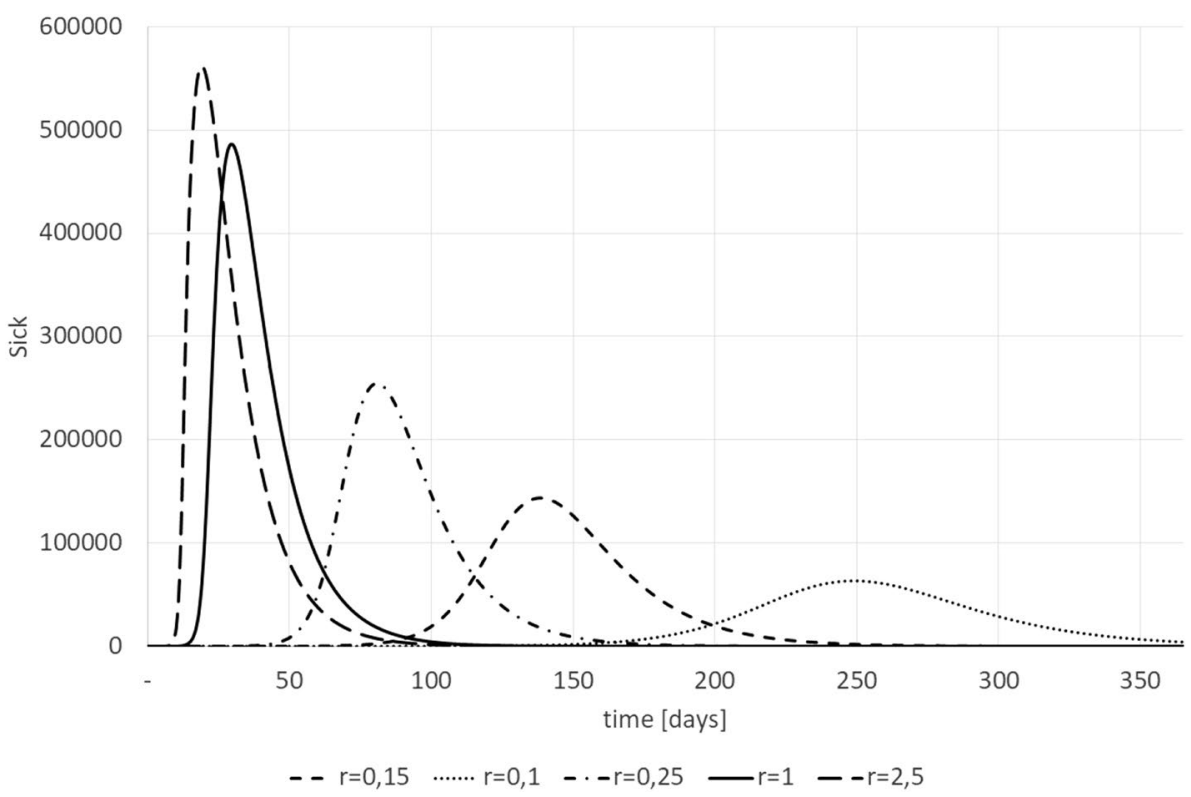

- Thorough literature analysis The existing literature (including existing models) should be properly analysed to determine structures and parameters.

- Calibration The model must be calibrated until it fits existing data as closely as possible, i.e. until the simulated results are close to the real data [26].

- Sensitivity analyses Parameters must be altered and consequences recorded [27] to develop a measure how reliable the results are as basis for decision-making.

- Scenarios indicate the consequences of structural changes and parameter changes.

- Caution All results must be interpreted with great caution and humbleness. The scenarios will produce intervals of incidence and prevalence rates as well as bands of costeffectiveness that are the basis for political decisions. It is unlikely that the models produce the only one and right answer, but they will provide likelihoods.

Modelling Covid-19 only a few months after its breakout and under severe uncertainty will not produce all-andforever true figures. Instead, we should use these strategic models as "modelling for insights, not for numbers" [28]. They can serve the scientists and politicians to understand the system much better, to point at research gaps and to give some principle answers to urgent questions. These answers cannot be precise figures, but our modelling results will permit humble and cautious policy advice.

Acknowledgements Open Access funding provided by Projekt DEAL.

Open Access This article is licensed under a Creative Commons Attribution 4.0 International License, which permits use, sharing, adaptation, distribution and reproduction in any medium or format, as long as you give appropriate credit to the original author(s) and the source, 
provide a link to the Creative Commons licence, and indicate if changes were made. The images or other third party material in this article are included in the article's Creative Commons licence, unless indicated otherwise in a credit line to the material. If material is not included in the article's Creative Commons licence and your intended use is not permitted by statutory regulation or exceeds the permitted use, you will need to obtain permission directly from the copyright holder. To view a copy of this licence, visit http://creativecommons.org/licenses/by/4.0/.

\section{References}

1. Heymann, D.L., Shindo, N.: COVID-19: what is next for public health? Lancet 395(10224), 542-545 (2020)

2. Hopkins, J: Corona Resource Center. https://coronavirus.jhu.edu/ (2020). Accessed 4 May 2020

3. Tan-Torres, E.T., World Health Organization: Making choices in health: WHO guide to cost-effectiveness analysis. World Health Organization, Geneva (2003)

4. Vivanco-Lira, A.: Predicting COVID-19 distribution in Mexico through a discrete and time-dependent Markov chain and an SIRlike model. arXiv preprint arXiv:2003.06758 (2020)

5. Song, P.X., et al.: An epidemiological forecast model and software assessing interventions on COVID-19 epidemic in China. medRxiv (2020). https://doi.org/10.1101/2020.02.29.20029421

6. Liu, Y.: Estimating the case fatality rate for COVID-19: a Markov model application. https://doi.org/10.2139/ssrn.3558612

7. Arumugam, R., Rajathi, M.: A Markov model for prediction of corona virus COVID-19 in India-a statistical study. J. Xidian Univ. 14(4), 1422-1426 (2020)

8. Atkeson, A.: What will be the economic impact of COVID-19 in the US? Rough estimates of disease scenarios. National Bureau of Economic Research, Cambridge (2020)

9. Homer, J.B., Hirsch, G.B.: System dynamics modeling for public health: background and opportunities. Am. J. Public Health 96(3), 452-458 (2006)

10. Fleßa, S.: Disease dynamics. Simulation epidemiologischer Prozesse mit Methoden des Operations Research. OR-News 23, 18-20 (2005)

11. Peng, L., et al.: Epidemic analysis of COVID-19 in China by dynamical modeling. arXiv preprint arXiv:2002.06563 (2020)

12. Jia, J., et al.: Modeling the control of COVID-19: Impact of policy interventions and meteorological factors. arXiv preprint arXiv:2003.02985 (2020)

13. Sterman, J.: Business Dynamics. McGraw-Hill, Boston (2016)

14. Ärzteblatt, D.: COVID-19: case-fatality-rate steigt mit dem Alter stark an. https://www.aerzteblatt.de/nachrichten/111220/COVID -19-Case-Fatality-Rate-steigt-mit-dem-Alter-stark-an (2020). Accessed 6 May 2020.
15. WHO: Q\&A on coronaviruses (COVID-19). https://www.who.int/ news-room/q-a-detail/q-a-coronaviruses (2020). Accessed 6 May 2020

16. Aronson, J., J. Brassey, K. Mahtan: "When will it be over?" An introduction to viral reproductive numbers, R0 and Re. https:// www.cebm.net/covid-19/when-will-it-be-over-an-introduction-toviral-reproduction-numbers-r0-and-re/ (2020). Accessed 6 May 2020

17. McKenzie, F.E., Wong, R.C., Bossert, W.H.: Discrete-event simulation models of Plasmodium falciparum malaria. Simulation 71(4), 250-261 (1998)

18. Rauner, M.S., Brailsford, S.C., Fleßa, S.: The use of discrete-event simulation to evaluate strategies for the prevention of mother-tochild transmission of HIV in developing countries. J. Oper. Res. Soc. 56, 222-233 (2005)

19. Siebers, P.-O., et al.: Discrete-event simulation is dead, long live agent-based simulation! J. Simulat. 4(3), 204-210 (2010)

20. Patlolla, P., et al.: Agent-based simulation tools in computational epidemiology. In: International Workshop on Innovative Internet Community Systems. Springer (2004)

21. D'Orazio, M., G. Bernardini, E. Quagliarini: How to restart? An agent-based simulation model towards the definition of strategies for COVID-19 "second phase" in public buildings. arXiv preprint arXiv:2004.12927 (2020)

22. Cecconi, F., Barazzetti, A.: Agent-based simulation model applied to social behaviors determining the dynamics of pandemics. United Campus of Malta (2020). https://ucm.edu.mt/en/agent -based-simulation-model-applied-to-social-behaviors-determinin g-the-dynamics-of-pandemics/. Accessed 29 May 2020

23. Pitman, R., et al.: Dynamic transmission modeling: a report of the ISPOR-SMDM modeling good research practices task force-5. Value Health 15(6), 828-834 (2012)

24. Hey, J.D., Lotito, G., Maffioletti, A.: The descriptive and predictive adequacy of theories of decision making under uncertainty/ ambiguity. J. Risk Uncertain. 41(2), 81-111 (2010)

25. Briggs, A.H., et al.: Model parameter estimation and uncertainty: a report of the ISPOR-SMDM modeling good research practices task force-6. Value Health 15(6), 835-842 (2012)

26. Karnon, J., Vanni, T.: Calibrating models in economic evaluation. Pharmacoeconomics 29(1), 51-62 (2011)

27. Sharif, B., et al.: Uncertainty analysis in population-based disease microsimulation models. Epidemiol. Res. Int. 2012, 610405 (2012). https://doi.org/10.1155/2012/610405

28. Peace, J., Weyant, J.: Insights not numbers: the appropriate use of economic models. Pew Center on Global Climate Change, Arlington $(2008)$

Publisher's Note Springer Nature remains neutral with regard to jurisdictional claims in published maps and institutional affiliations. 